\title{
AS RELAÇÕES ÉTNICO-RACIAIS E OS CURRÍCULOS DOS CURSOS DE LICENCIATURA DE UMA UNIVERSIDADE DO MATO GROSSO DO SUL
}

\author{
Felipe de Lima Silva ${ }^{1}$, Andressa Florcena Gama da Costa ${ }^{2}$, Thalita Pereira da Silva ${ }^{3}$ \\ ${ }^{1}$ Graduado em Zootecnia pela Universidade Estadual Paulista - UNESP e Graduando em Pedagogia na Universidade \\ Federal do Mato Grosso do Sul - UFMS, com participação no Programa Institucional de Iniciação a Docência - PIBID. \\ ${ }^{2}$ Doutoranda no Programa de pós-graduação em Educação da Universidade Estadual Paulista - UNESP. Professora \\ Assistente do curso de Pedagogia na Fundação Universidade Federal de Mato Grosso do Sul - UFMS. E-mail: \\ andressaflorcena@hotmail.com \\ ${ }^{3}$ Graduanda do curso de Pedagogia pela Universidade Federal de Mato Grosso do Sul - UFMS e bolsista do programa \\ Residência Pedagógica. Professora Bilíngue pela Fundação Lowtons de Educação e Cultura - FUNLEC.
}

\section{RESUMO}

Este artigo contempla uma investigação sobre as relações étnico-raciais no currículo de todos os cursos de licenciatura de uma instituição de ensino superior localizada no estado de Mato Grosso do Sul. O estado é o segundo em número de habitantes ameríndios e de várias etnias e localiza-se na fronteira com outros países constituindo-se em um estado multicultural. Levando em consideração o papel dos cursos de graduação em preparar o futuro professor para abordar os temas de etnia e diversidade nas escolas, tivemos por objetivo analisar o atendimento da lei no 10639/03 por parte das licenciaturas de todos os campus de uma instituição de ensino superior, vislumbrando dessa forma a discussão sobre como as relações étnico-raciais são tratadas no currículo das licenciaturas no que diz respeito as práticas de ensino para a igualdade. Para tanto, abordamos a temática com base em uma revisão bibliográfica sobre a educação e as relações étnico-raciais segundo as legislações brasileiras. Apoiados pela metodologia de pesquisa qualitativa do tipo exploratória recorremos a uma análise documental nas grades curriculares dos cursos de licenciatura. Os resultados evidenciam que em algumas licenciaturas a discussão sobre a diversidade étnico-racial são silenciadas, pois não estão presentes no currículo da formação, nos demais cursos localizamos uma imensa variedade de abordagens, carga horária distintas que em seu conjunto evidenciam também o comprometimento ou não dos cursos com a questão analisada. As análises reforçam a necessidade de processos formativos que sejam capazes de combater discursos e narrativas carregadas de estereótipos e preconceitos.

Palavras-chave: Currículo. Preconceito. Formação de Professores. Diversidade Étnico-Racial.

\section{THE ETHNIC-RACIAL RELATIONS AND THE CURRICULUM OF THE DEGREE COURSES AT A UNIVERSITY IN THE STATE OF MATO GROSSO DO SUL}

\section{ABSTRACT}

This article includes an investigation of ethnic-racial relations in the curriculum of all undergraduate courses of a higher education institution located in the state of Mato Grosso do Sul. The state is the second in number of Amerindian inhabitants and of various ethnic groups and is located on the border with other countries constituting a multicultural state. Having regard to undergraduate courses role in preparing the future teacher to address the issues of ethnicity and diversity in schools, we aimed to analyze Law No. $10639 / 03$ by degrees courses of all campus of an higher education institution of , with a view to a discussion about how ethnic-racial relations are treated in the curriculum of undergraduate degrees with respect to teaching practices for equality. To do this, we approached the topic based on a bibliographic review about the education and ethnic-racial relations according to the Brazilian legislation. Supported by the methodology of qualitative research of exploratory type, we performed a detailed curricular documentary analysis of undergraduate courses. The results showed that in some undergraduate courses the discussion of ethnic-racial diversity is silenced, because this doesn't make part of the curriculum, in other courses we 
find a wide variety of approaches, different workloads that together also evidence the commitment or not of the courses with the issue analyzed. The analyses reinforce the need of formative processes of being able to combat discourses and narratives loaded with a lot of stereotypes and prejudices.

Keywords: Curriculum. Prejudice. Teacher training. Ethnic-Racial Diversity.

\section{RELACIONES ÉTICO-RACIALES Y CURRICULUM DE CURSOS DE LICENCIA DE UNA UNIVERSIDAD DE MATO GROSSO DO SUL}

Resumen: Este documento aborda una investigación de las relaciones étnico-raciales en el plan de estudios de todos los institutos de profesorado de una institución de educación superior ubicada en el estado de Mato Grosso do Sul. El estado es el segundo en número de habitantes amerindios y multiétnicos y está ubicado frontera con otros países que constituyen un estado multicultural. Teniendo en cuenta el papel de los cursos de preparación del futuro docente para abordar los problemas de origen étnico y diversidad en las escuelas, nuestro objetivo fue analizar el cumplimiento de la Ley $N^{\circ} 10639 / 03$ por todos los títulos de pregrado en una institución educativa. Imaginando así una discusión sobre cómo se tratan las relaciones étnico-raciales en el plan de estudios de formacion con respecto a las prácticas de enseñanza para la igualdad. Por lo tanto, abordamos el tema en base a una revisión bibliográfica sobre Educación y relaciones étnico-raciales de acuerdo con la legislación brasileña. Con el apoyo de la metodología de investigación cualitativa exploratoria, recurrimos a un análisis documental en las redes curriculares de los cursos de formacion. Los resultados muestran que en algunos institutos de profesorado silencia la discusión sobre la diversidad étnico-racial, ya que no están presentes en el plan de estudios de capacitación, en los otros cursos encontramos una inmensa variedad de enfoques, carga de trabajo distinta que también muestra el compromiso o no de los cursos con la pregunta analizada. Los análisis refuerzan la necesidad de procesos formativos capaces de combatir discursos y narrativas cargados de estereotipos y prejuicios.

Palabras clave: Plan de estúdios. Prejuicio. Formación de profesores. Diversidad étnico-racial.

\section{INTRODUÇÃO}

$O$ artigo tem origem no encerramento da disciplina Teoria e Prática em Diversidade Étnico Racial ministrada no quarto semestre do curso de licenciatura em Pedagogia em uma Universidade situada no estado do Mato Grosso do Sul (MS). A partir da análise da problemática discutida durante os encontros e dados nacionais que apontam o estado de Mato Grosso do sul como o segundo em número de habitantes ameríndios e de várias etnias, vislumbramos a possibilidade de realizar um levantamento com base na grade curricular de todas as licenciaturas ofertadas pela Universidade, a fim de responder a seguinte questão: $O$ currículo ofertado pela instituição atende ao texto da política para as licenciaturas de modo que potencialize a formação docente e as práticas de ensino para a igualdade étnica ou representam uma mera formalidade? Para tanto, buscamos observar como a temática está inserida no currículo dos cursos de licenciatura, considerando esta, fundamental para o preparo do futuro docente no trabalho e abordagem sobre as questões étnico-raciais com as crianças, jovens e ou adultos.
Considerado como patrimônio da humanidade, o estado de Mato Grosso do Sul, além de ser um dos mais ricos em diversidade ambiental é também um dos estados com maior diversidade em etnias. Localizado na região Centro-Oeste do Brasil, a população sul-matogrossense apresentou um grande crescimento a partir da segunda metade do século XIX, dado este que contribui para o povoamento, além de estabelecer, em um mesmo território, uma pluralidade cultural.

O Mato Grosso do Sul abriga hoje grande parte da população parda do Brasil, assim como se constitui espaço de resistência para povos indígenas tais como, Guarani Kaiowá, Guarani Ñandeva, Guató, Kadiwéu, Kiniquinau, Ofaié, Terena, entre outros e comunidades quilombolas como, Furnas do Dionísio, Furna da Boa Sorte, Comunidade Tia Eva, Comunidade São João Batista, todas representando a preservação de saberes, costumes e suas tradições culturais.

Diante de tal diversidade populacional no estado, merece ser destacada a responsabilidade social atribuída às instituições de ensino superior no sentido de valorizar saberes e povos tão 
importantes ao nosso país, sendo uma de suas tarefas promover 0 reconhecimento das identidades e combater estereótipos e preconceitos, oferecendo uma educação e formação que contemple as relações étnicoraciais, não excluindo a necessidade do trato dessas questões no âmbito das licenciaturas.

O próprio espaço universitário já propicia - convívio das mais diferentes culturas entretanto, por mais diversificado e democrático que este espaço possa ser, há de se considerar que o preparo para o exercício da docência requer, sobretudo, uma gama imensa de propostas pedagógicas que envolvam não somente carga horária teórica, a partir da qual as teorias pós-modernas ou do multiculturalismo poderiam dar suporte ao ensino de conteúdos escolares, mas também práticas que aproximem os acadêmicos das diferentes culturas e propiciem uma ampla discussão e compreensão das relações étnico-raciais. Apesar da obrigatoriedade do ensino sobre História e Cultura Afro-Brasileira nas grades curriculares dos ensinos fundamental e médio asseguradas pela lei 10639/03 a oferta de uma disciplina que contemple as questões étnico-raciais nem sempre é obrigatória nos cursos de graduação (BRASIL, 2003).

Alguns cursos ofertaram disciplinas que tratam das questões étnico-raciais de forma indispensável na formação inicial, enquanto outros cursos de licenciatura ofertam somente como optativa, possibilitando que o aluno escolha cursar ou não. Diante disso, a não obrigatoriedade ou a ausência de carga horária suficiente, resulta que o discente só discuta tais questões caso as considere pertinente para sua formação.

Por tratar-se de uma investigação qualitativa do tipo exploratória (GIL, 2008), nos aproximamos da temática de modo a "proporcionar maior familiaridade com o problema, com vistas a torná-lo mais explícito" (GIL, 2008, p. 41) assim consideramos para fins de análise apenas a grade curricular de todos os cursos de licenciatura de uma instituição do interior do estado de MS. Contudo, sabemos que além do espaço da sala de aula, as licenciaturas propiciam espaços como grupos de estudo e pesquisa e iniciativas de extensão que contemplam as questões étnico-raciais, como oficinas e outras ações integradas ao Programa de Educação Tutorial (PET) e anteriormente no extinto PIBID-diversidade. Embora tais práticas aconteçam, nem todos acadêmicos são contemplados e espera-se cada vez mais que os currículos das licenciaturas sejam capazes de levar em consideração a necessidade de potencializar a formação de professores, de modo a promover ações integradas ao tripé de ensino, pesquisa e extensão posposto pela universidade, contribuindo com uma pedagogia da alteridade e da diversidade.

Os cursos de licenciatura constituem os alicerces para a formação de professores capazes de assegurar uma educação de qualidade em suas diversas esferas, o que exige empenho no preparo do futuro docente para a igualdade racial.

Diante disso, a oferta de uma disciplina que trate das questões étnico-raciais nos cursos torna-se essencial para a formação de profissionais qualificados. Para tanto, é necessário um arranjo curricular nos projetos dos cursos, potencializando os processos de formação e construindo um currículo comprometido em formar indivíduos capazes de combater qualquer preconceito e discriminação racial presentes na sociedade.

Neste trabalho, pretende-se olhar a temática enfatizando três aspectos: primeiro analisar-se-á algumas das legislações étnicoraciais vigentes no Brasil; segundo, será destacada a formação docente, apresentando e discutindo sua importância para a formação dos profissionais para o trato das questões raciais, propondo estratégias e ações que podem contribuir para a discussão e devida valorização da temática no contexto educativo; e por fim, nos resultados e discussões, serão feitas análises com base na grade curricular dos cursos de licenciatura de uma Universidade do estado do Mato Grosso do Sul, buscando verificar quais cursos ofertam disciplinas que contemplem a temática, bem como as cargas horárias, refletindo sobre o currículo ofertado pela instituição e as práticas de ensino para a igualdade.

\section{A EDUCAÇÃO E AS RELAÇÕES ÉTNICO-RACIAIS SEGUNDO AS LEGISLAÇÕES BRASILEIRAS}

A educação no Brasil tem seu conceito e preceitos firmados na carta magna que rege 0 país (BRASIL, 1988), assim "A educação, direito de todos e dever do Estado e da família, será promovida e incentivada com a colaboração da sociedade, visando ao pleno desenvolvimento da pessoa, seu preparo para o exercício da cidadania 
e sua qualificação para o trabalho". A Constituição Federal demarca que a mesma será regida por preceitos democráticos como, pluralismo de ideias e liberdade configurando a base de uma educação capaz de transformar pessoas e a sociedade, como afirmava Paulo Freire.

A sociedade brasileira, considerada plural, abrange uma gama imensa no que diz respeito à diversidade e, em decorrência disso, é papel da educação contemplar essa diversidade. Por ser um espaço de aprendizagem da convivência, nela se encontram reunidas diferentes etnias e, portanto, a mesma deve prezar pelo espírito de democracia.

Segundo Gadotti (1992, p. 21),

A escola que se insere nessa perspectiva procura abrir os horizontes de seus alunos para a compreensão de outras culturas, de outras linguagens e modos de pensar, num mundo cada vez mais próximo, procurando construir uma sociedade pluralista.

A lei 10639/03, por exemplo, é um dos instrumentos cujo princípio está em oportunizar e garantir o ensino e valorização da História e Cultura Afro-Brasileira, já que no período pós abolição da escravatura a educação representou à população negra uma chance de alcançar novos postos e enfrentar a desvalorização posta diante da cultura hegemônica dos/as brancos/as numa sociedade em pleno processo de modernização (BRASIL, 2003).

Podemos destacar também a implementação da lei no 11645 de 10 de março de 2008 que altera um artigo da Lei de Diretrizes e Bases - LDB. A partir dessa lei a temática histórico cultural afro-brasileira que já era obrigatória, passa a dividir espaço com a cultura indígena onde ambos os temas se tornam parte do currículo de todas as escolas públicas e particulares cujo objetivo não é a criação de novas disciplinas com tal temática, mas sim tratálas como tema transversal nas já existentes (BRASIL, 2008).

Destacamos também a importância da lei 12.711, de 29 de agosto de 2012, que destina $50 \%$ das vagas dos vestibulares das instituições de nível técnico e superior para negros (BRASIL, 2012). Num país onde $55,8 \%$ da população se considera negra/parda (IBGE, 2018), o governo usa da estratégia de políticas afirmativas para a abertura de vagas no nível superior para a população afrodescendente, porém carece ainda um maior investimento na educação básica e de qualidade para os mesmos. Tal legislação é um instrumento precursor de mudanças significativas na democratização do acesso ao ensino superior e na redução da desigualdade social no país, mas ainda divide a sociedade entre os que acreditam na medida como ferramenta de integração social, étnica e racial e retratação histórica e, de outro lado, aqueles que consideram que a medida fere a autonomia universitária e o princípio de igualdade e meritocracia pois o nível de dificuldade de acesso garantiria uma suposta "qualidade" nos cursos, deste ponto de vista, reforçando a ideia de que a educação superior é destinada a poucos.

O Estatuto da Criança e do Adolescente, carece ser mencionado também pois, a partir da lei 8069 de 13 de julho de 1990, dispõe em seu artigo 5o que nenhuma criança ou adolescente será objeto de qualquer forma de negligência, discriminação, exploração, violência, crueldade e opressão considerando a punição para qualquer atentado que venha por ação ou omissão afetar os direitos fundamentais da criança e do adolescente (BRASIL, 1990).

A nível de propostas curriculares para a educação básica, podemos mencionar a iniciativa dos Parâmetros Curriculares Nacionais Pluralidade Cultural - (BRASIL, 1998) apesar de receber inúmeras críticas do setor educacional, merece o crédito por incluir a temática ao nível de uma proposta curricular para a escola, o que já é um grande avanço para ser considerado, ou, cabendo então ao profissional da educação estar atento as modificações que perpassam na sociedade.

Segundo as Diretrizes Curriculares Nacionais (2005), o Brasil ao longo da sua História, estabeleceu um modelo de desenvolvimento excludente, impedindo que milhões de brasileiros tivessem acesso à escola ou nela permanecessem. É o que pode ser constatado no Decreto de no 1.331 de 17 de fevereiro de 1854 , onde se estabelecia que nas escolas públicas do país não fossem admitidos escravos, e a previsão de instrução para adultos negros dependia da disponibilidade de professores. Já o Decreto de № 7.031 - A, de 6 de setembro de 1878, estabelecia que os negros só podiam estudar no período noturno cujo os 
obstáculos sociais foram montados no sentido de impedir o acesso pleno dessa população aos bancos escolares.

A obrigatoriedade da inclusão de História e Cultura Afro-Brasileira e Africana nos currículos da Educação Básica nada mais é do que uma decisão política com grande repercussão inclusive para a formação de professores. Essa é uma decisão que valoriza devidamente a história e cultura dos povos, numa tentativa de reparar danos que se repetem por tanto tempo.

A relevância do estudo de temas decorrentes da História e cultura afro-brasileira e africana não se restringe à população negra ou indígena ao contrário, diz respeito a todos brasileiros, uma vez que devem educar-se enquanto cidadãos atuantes no seio de uma sociedade multicultural e pluriétnica, capaz de construir uma nação democrática (BRASIL, 2005).

\section{A FORMAÇÃO E PRÁTICA DOCENTE}

A educação assume papel primordial no combate ao racismo e na discussão sobre a formação para a consciência das desigualdades raciais. Diante de tal situação, uma série de aspectos legais têm sido implementados nas escolas do país, a fim de desconstruir tais práticas preconceituosas. Para Fleuri (2003), o objetivo de uma educação antirracista se dá na promoção de atividades educativas que visam 0 aprofundamento da consciência de cada um com o objetivo de propor a identificação e o desmonte de práticas preconceituosas implícitas ou explícitas, pessoais ou institucionais.

Nosso envolvimento com a temática tornou-se maior durante a disciplina de Teoria e Prática em Diversidade Étnico-Racial, da graduação em Pedagogia, na qual após levantamento realizado por questionário aplicado entre os acadêmicos de várias idades foi possível verificar que tanto a escola e a universidade ainda representam um espaço no qual ocorrem muitos casos de racismo, preconceito e discriminação. Mais alarmante que esse dado, é o fato da temática ser abordada somente em datas comemorativas e tratada apenas como parte do rico folclore brasileiro.

Partindo dessas considerações, muitas vezes o professor não consegue abordar a temática étnico-racial por falta de experiência e, até mesmo de qualificação. Muitas práticas de ensino ainda estão baseadas no mito da democracia racial, comprometendo o processo de formação de crianças, jovens e adultos.
Dada a relevância da atuação docente no contexto educativo geral, Dias (2012) ressalta que o combate ao racismo na sociedade brasileira só pode ser fomentado a partir de ações na educação escolar e na formação de professores e com isso as mobilizações sociais provocam, em diferentes níveis governamentais, a criação de programas ou atividades de estímulo à diversidade étnico-racial nos programas de ensino.

Para Dias (2012) é a partir da temática vivenciada que os indivíduos se apropriam dos conhecimentos oferecidos no seu processo de formação, mobilizando suas histórias pessoais com o tema de discriminação, às vezes com situações em que o próprio foi a vítima.

Ainda segundo Dias (2012), o professor deve ter coragem para enfrentar questões da temática preconceito racial no seu trabalho docente, incluindo conhecimentos afrobrasileiros e indígenas e considerá-los tão importantes quanto os conhecimentos de origem europeia, que já são largamente trabalhados, rompendo com uma tradição eurocêntrica de currículo, atitude nem sempre apoiada pelo conjunto de profissionais das instituições escolares.

Nessa perspectiva, a formação docente assume lugar central, e para Zeichner (2000) um programa de formação inicial deve estar comprometido com a vivência na escola e sua realidade. $\mathrm{O}$ autor revela ainda que, no programa de formação da universidade em que atua a formação multicultural tem sido o carro forte. Porém, "[...] é ainda muito acadêmico. Eles leem sobre temas, há pessoas que vem visitar as salas de aula, mas eles não estão imersos na comunidade".

Zeichner (2000) ainda aponta uma grave situação da licenciatura, uma vez que "temos pessoas adquirindo conhecimentos novos e novas habilidades, mas, em geral, elas não se tornam pessoas diferentes". O autor aposta em situações de imersão e vivência cultural na comunidade onde lecionará o professor dado que "muitos de nossos estudantes têm pouca experiência intercultural direta. Eles podem ter crescido em Los Angeles e nunca terem ido a comunidades latinas, porque vivem em Beverly Hills ou lugares assim".

Assim, cada vez mais, reconhece-se a importância da escola enquanto espaço de aprendizagem da docência, e os períodos de imersão na realidade escolar, tal como podem ser 
os estágios e Residência Pedagógica (no modelo idealizado pela Unifesp) poderiam contribuir para tal apropriação cultural.

O professor pode buscar no patrimônio cultural brasileiro e mundial referências que levem as crianças a conhecer e vivenciar a história e a cultura afro-brasileira e indígena de modo que aprendam a valorizá-las. Trabalhar com esse patrimônio e com as suas diferentes linguagens é essencial para uma contribuição para se construir novos olhares sobre as histórias e as heranças culturais desses grupos tão importantes para a formação do povo brasileiro, mas ainda insuficientemente valorizadas no currículo da educação infantil (DIAS, 2012).

A abordagem apresentada nos próprios produtos de entretenimento oferecido para as crianças tem fortes referências estereotipadas, sobretudo ao apresentar apenas um único tipo físico como portador das virtudes humanas (XAVIER, 2014).

O mesmo acontece, na maioria das vezes, com a Literatura Infantil, especialmente nos contos de fadas, que apesar de importantes para a formação das crianças, foram gradativamente sendo modificados para adaptarem-se ao modelo de sociedade, e em decorrência disso, transformaram-se em veículo de reprodução das desigualdades, tornando-se coadjuvantes no condicionamento de estereótipos já enraizados na sociedade. É importante apresentar para as crianças outras vertentes, como por exemplo a literatura de Daniel Munduruku, para que consigam se reconhecer como sujeito de si perante ao outro. Dias $(2012$, p. 667) ressalta ainda que:

[...] consideramos as crianças sujeitos ativos e reflexivos, não podemos obrigá-las a assumir uma identidade, seja ela qual for, ainda que acreditemos ser mais saudável que uma criança negra (aos nossos olhos) se aceite, tenha orgulho de si e dos seus antepassados; a identidade, inclusive a étnico-racial, socialmente construída [...].

Com efeito, não cabe ao professor impor uma identidade a criança, seja ela qual for. $O$ que o professor tem como obrigação é proporcionar elementos positivos que vão possibilitar que as crianças sejam capazes de se apoiar na constituição de suas identidades, por vezes híbridas.

Sabemos que algumas experiências de aprendizagem informais da docência exercem forte influência nos futuros professores, sendo uma destas fontes de aprendizagem informal os modelos para o ensino nas práticas de seus antigos professores, cuja situação se agrava quando este "[...] saber herdado da experiência escolar anterior é muito forte, que ele persiste através do tempo e que a formação universitária não consegue transformá-lo nem muito menos abalá-lo" (TARDIF, 2005, p. 20).

Os temas debatidos apontam a necessidade de investir em uma formação de professores que valorize o contexto cultural e social que o mesmo se propõe a atuar. De acordo com Silva e Ferreira (2006) e Dias (2012), é necessário que as instituições de ensino superior do país tenham a preocupação em propiciar aos futuros educadores uma formação adequada que esteja de acordo com as leis que regem tal temática.

Para Dias (2012), a construção de uma identidade positiva não poderá ser de fato contemplada em sua integridade se as instituições educativas ignorarem a dimensão étnico-racial presente na comunidade brasileira. Tão importante quanto seria a necessidade dos cursos de formação de professores conseguirem capacitar, ou pelos menos incentivar o profissional para que ele ajude a criança a se apropriar dos conhecimentos culturais e científicos produzidos pelos vários grupos étnicoraciais, incluindo negros e indígenas.

Dessa forma, "podem ter mudado os sistemas econômicos, as relações de trabalho e as formas de opressão, porém os negros continuam a ser ideologicamente definidos como inferiores" (VALENTE, 1987, p.58).

O professor é uma das figuras centrais que deve mobilizar-se a construir uma atmosfera positiva dentro da sala de aula, incluindo a criança negra/indígena para que a mesma jamais se sinta excluída ou deixada de lado nas interações com a turma, e a instituição deve proporcionar momentos de discussão e estudo do assunto, propiciando o compromisso com o combate ao racismo como uma necessidade premente no ambiente escolar.

Nesse sentido, a qualificação dos profissionais da educação se torna imprescindível 
para que se possa lidar com as relações produzidas pelo racismo e a discriminação no ambiente escolar. A qualificação deve envolver de forma complexa esses indivíduos.

O professor deve possuir a capacidade de ser crítico com a sua própria prática tendo atitudes reflexivas nos acontecimentos escolares ligando os mesmos aos conhecimentos já adquiridos através do seu embasamento teórico e qualificação, pois tais atitudes promovem a construção de novas práticas positivas no trato da informação étnico-racial.

\section{DELINEAMENTO METODOLÓGICO}

A pesquisa apresentada busca levantar dados que possibilitem a análise a partir do atendimento da lei no 10639/03 por parte das licenciaturas de uma instituição de ensino superior. A abordagem adotada foi a qualitativa de cunho exploratório, idealizada no século XIX com a concepção de que a vida individual deve ser vista como algo importante a ser analisado a partir da priorização de pequenas amostras, buscando compreender a perspectiva de cada um dos seus entrevistados (BARROS; LEHFELD, 1990).

Para iniciarmos a nossa pesquisa, fizemos um levantamento com base nas grades curriculares de todas as licenciaturas de uma Universidade Pública no estado do Mato Grosso do Sul, considerando os cursos que abordam e preparam o futuro professor para atuar com questões de etnia, voltando o nosso olhar para a nomenclatura da disciplina, a sua carga horária e presença/ausência na grade curricular.

É importante levarmos em consideração que, embora o universo pesquisado sejam os cursos de licenciatura de determinada instituição, as discussões e os resultados da pesquisa poderão suscitar outras reflexões quanto aos limites e as possibilidades da formação de professores para as relações étnico-raciais nas demais universidades do território brasileiro. As análises aqui descritas são apresentadas a seguir.

\section{RESULTADOS E DISCUSSÕES}

Quando observamos a análise feita nos cursos de licenciatura da instituição de ensino escolhida, percebemos uma gama imensa de carga horária e nomenclaturas diferentes das disciplinas relacionadas às temáticas aqui discutidas.

Partindo desse grande leque das nomenclaturas das disciplinas, podemos trazer à tona que as diferenças ou similaridades encontradas em nossas análises são concernentes ao contexto para a inserção da "educação das relações étnico-raciais" que consta na resolução no 01 de 17 de junho de 2004, na qual nos deparamos com a seguinte descrição:

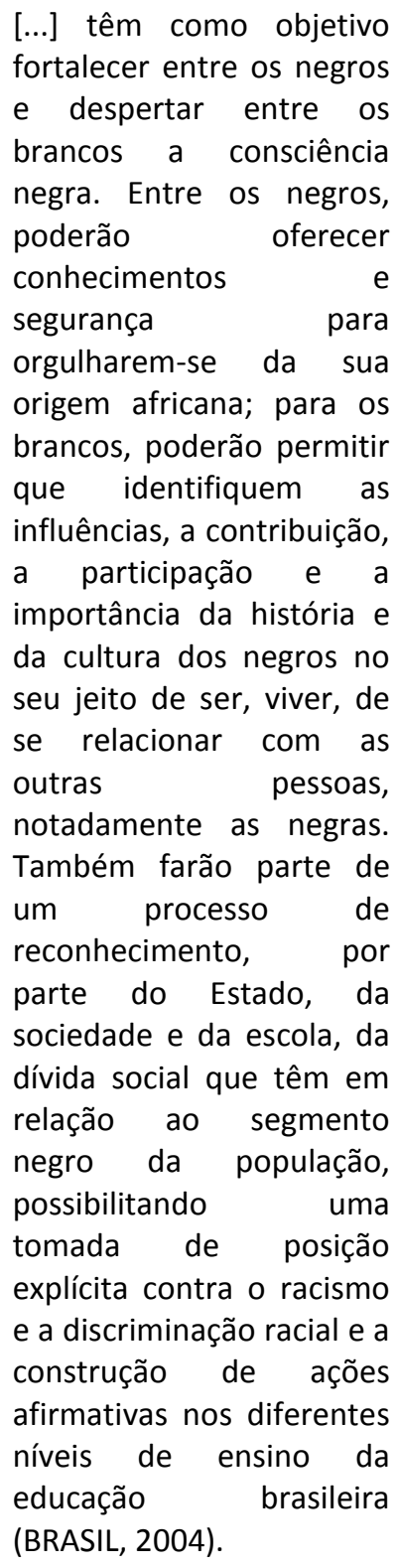

É a partir desses objetivos encontrados na legislação com a inserção da temática em sala de aula que construiremos o currículo da mesma, e para Silva (2011), o currículo depende precisamente daquilo que $o$ define pelos diferentes autores e teorias, já que a sua constituição não nos revelará o que é currículo, mas sim o que uma determinada teoria pensa o que o currículo é. Considerá-lo como um campo de estudo exige compreender a construção histórica do conceito de "raça", como ele opera nas relações sociais e suas consequências nos 
processos escolares e na formação de professores.
Assim, passaremos à apresentação dos dados que compõem as análises neste artigo.

Quadro 1. Listagem das Disciplinas Étnico-Raciais oferecidas nos Campus da instituição de ensino Superior

\begin{tabular}{|c|c|c|c|c|}
\hline Cidade & Curso & Oferta & Disciplina & $\begin{array}{l}\text { Carga } \\
\text { Horária }\end{array}$ \\
\hline \multirow[t]{7}{*}{ Aquidauana } & $\begin{array}{l}\text { Ciências } \\
\text { Biológicas }\end{array}$ & Sim & História da África e cultura afro-brasileira* & 51 \\
\hline & Geografia & Sim & Educação das relações étnico-raciais* & 51 \\
\hline & História & Sim & História da África e cultura afro-brasileira & 51 \\
\hline & Letras & Sim & História da África e cultura afro-brasileira & 68 \\
\hline & $\begin{array}{l}\text { Licenciatura } \\
\text { Indígena }\end{array}$ & Sim & $\begin{array}{l}\text { História e antropologia indígena e afro- } \\
\text { brasileira }\end{array}$ & 68 \\
\hline & Matemática & Sim & Educação das relações étnico raciais & 51 \\
\hline & Pedagogia & Sim & Educação das relações étnico raciais & 51 \\
\hline \multirow[t]{18}{*}{ Campo Grande } & Filosofia & Sim & Educação das relações étnico-raciais* & 51 \\
\hline & \multirow[t]{4}{*}{ História } & \multirow[t]{4}{*}{ Sim } & Educação das relações étnico-raciais & 51 \\
\hline & & & História da África * & 68 \\
\hline & & & $\begin{array}{l}\text { Ensino de história e cultura afro-brasileira e } \\
\text { africana }\end{array}$ & 68 \\
\hline & & & $\begin{array}{l}\text { Religiões afrodescendentes no Mato Grosso } \\
\text { do Sul* }\end{array}$ & 68 \\
\hline & $\begin{array}{l}\text { Educação do } \\
\text { Campo }\end{array}$ & Não & & \\
\hline & Educação Física & Sim & Educação das relações étnico-raciais & 51 \\
\hline & \multirow[t]{2}{*}{ Pedagogia } & \multirow{2}{*}{ Sim } & Relações étnico-raciais & 68 \\
\hline & & & História da África * & 68 \\
\hline & Artes Visuais & Sim & Educação das relações étnico-raciais & 51 \\
\hline & \multirow[t]{2}{*}{ Letras } & \multirow[t]{2}{*}{ Sim } & Educação das relações étnico-raciais* & 34 \\
\hline & & & $\begin{array}{l}\text { Aspectos da tipologia de línguas negro- } \\
\text { africanas* }\end{array}$ & 34 \\
\hline & Música & Sim & Educação das relações étnico-raciais & 51 \\
\hline & $\begin{array}{l}\text { Ciências } \\
\text { Biológicas }\end{array}$ & Sim & Educação das relações étnico-raciais & 34 \\
\hline & Geografia & Sim & Educação das relações étnico-raciais* & 51 \\
\hline & Física & Sim & Educação das relações étnico-raciais & 51 \\
\hline & Matemática & Sim & Educação das relações étnico-raciais & 51 \\
\hline & Química & Sim & Educação das relações étnico-raciais* & 51 \\
\hline \multirow[t]{8}{*}{ Corumbá } & $\begin{array}{l}\text { Ciências } \\
\text { Biológicas }\end{array}$ & Sim & Educação das relações étnico-raciais & 34 \\
\hline & Educação Física & Não & & \\
\hline & Geografia & Não & & \\
\hline & \multirow[t]{2}{*}{ História } & \multirow[t]{2}{*}{ Sim } & Educação das relações étnico-raciais & 34 \\
\hline & & & História da África & 68 \\
\hline & Letras & Sim & Educação das relações étnico-raciais & 34 \\
\hline & Matemática & Sim & Educação das relações étnico-raciais & 34 \\
\hline & Pedagogia & Não & & \\
\hline \multirow[t]{2}{*}{ Coxim } & História & Sim & História da África e cultura afro-brasileira & 51 \\
\hline & Letras & Não & & \\
\hline \multirow[t]{2}{*}{ Naviraí } & Ciências Sociais & Sim & Estudos afro-brasileiros e étnico-raciais & 51 \\
\hline & Pedagogia & Sim & $\begin{array}{l}\text { Tópicos Educacionais em Educação e } \\
\text { Igualdade Étnico Racial }\end{array}$ & 51 \\
\hline \multirow[t]{2}{*}{ Nova Andradina } & \multirow[t]{2}{*}{ História } & \multirow[t]{2}{*}{ Sim } & História e cultura afro-brasileira & 68 \\
\hline & & & História da África & 68 \\
\hline
\end{tabular}




\begin{tabular}{|c|c|c|c|c|}
\hline Paranaíba & Matemática & Sim & Educação das relações étnico-raciais* & 51 \\
\hline \multirow[t]{2}{*}{ Ponta Porã } & Matemática & Sim & Estudos afro-brasileiros e étnico raciais* & 68 \\
\hline & Pedagogia & Sim & Estudos afro-brasileiros e étnico raciais* & 68 \\
\hline \multirow[t]{9}{*}{ Três Lagoas } & $\begin{array}{l}\text { Ciências } \\
\text { Biológicas }\end{array}$ & Não & & \\
\hline & Geografia & Sim & Cultura e relações étnico-raciais & 51 \\
\hline & \multirow[t]{4}{*}{ História } & \multirow[t]{4}{*}{$\operatorname{Sim}$} & Introdução a história da África & 68 \\
\hline & & & Educação das relações étnico-raciais & 51 \\
\hline & & & $\begin{array}{l}\text { Prática de ensino e pesquisa em história, } \\
\text { multiculturalismo, povos indígenas e } \\
\text { diversidade }\end{array}$ & 68 \\
\hline & & & História e culturas Africanas* & 68 \\
\hline & Letras & Sim & Educação das relações étnico-raciais & 34 \\
\hline & Matemática & Não & & \\
\hline & Pedagogia & Sim & Teoria e prática em diversidade étnico-racial & 68 \\
\hline
\end{tabular}

Fonte: (Autores, 2019)

Nota: Elaborado pelos autores com base nas grades curriculares dos cursos.

* disciplinas optativas.

O quadro sintetiza as informações de todas as licenciaturas que ofertam disciplinas relacionadas a discussão da temática étnico-racial na formação do futuro docente. Organizamos agrupando as informações por cidades que possuem campus da universidade analisada, relacionando a nomenclatura das disciplinas com a carga horária.

Algumas dessas disciplinas são consideradas optativas para a formação do docente; em nove cursos de licenciatura a única opção ofertada é na modalidade optativa e em outros sete cursos a disciplina sequer existe no currículo. Evidenciamos que a ausência de discussões relativas a temática, podem contribuir para que o futuro professor adote um comportamento de desinteresse ou invisibilidade da temática dentro de uma sala de aula, destruindo todo um histórico de luta e conquista dos movimentos negros e indígenas na sociedade brasileira. Gerando inclusive um conflito com as leis n. 10.639/03 (BRASIL, 2003) e 11.645/08 (BRASIL, 2008) que tornam indispensáveis o Ensino da História e Cultura Africana e Indígena em todo sistema de ensino.

Assim, analisando o quadro 1 observamos que nenhuma das disciplinas ofertadas ultrapassa a carga horária de 68 horas, o que dificulta o desenvolvimento de situações práticas de ensino que são, na maioria dos casos, essenciais para a formação do docente crítico e antenado com a sua realidade.

Em alguns cursos como de licenciatura em História encontramos mais de uma disciplina relacionada a temática, assim como em alguns cursos existem duas ou três disciplinas. A nomenclatura que mais comparece é "Educação das relações étnico-raciais" descrevendo a terminologia cunhada na resolução n. 01 de 2004, já apresentada anteriormente. Em apenas dois cursos existe a menção ao desenvolvimento de situações de prática de ensino em diversidade étnica, considerando que o estado possui populações indígenas e quilombolas, os demais cursos poderiam se atentar a essa possibilidade de integração e formação com a vivência da realidade.

A articulação ou alternância de momentos formativos teóricos e práticos certamente capacitam o egresso da licenciatura para um trabalho muito mais efetivo em sala de aula. As tendências da teoria pós-crítica: 0 multiculturalismo; o pós-estruturalismo; o póscolonialismo; os estudos culturais; os estudos feministas; as narrativas étnico-raciais; a teoria Queer, entre outros, são movimentos que possibilitam o questionamento de padrões hegemônicos que silenciam vozes e os saberes dos sujeitos subalternizados no interior da sociedade. Cardoso e Castro (2015) ressaltam ainda que a organização do currículo e das práticas pedagógicas que estão imersas em concepções homogeneizadoras, com um discurso de promoção de igualdade, quando não reconhecem as diferenças raciais $e$ os mecanismos sociais que produzem o racismo, contribuem para a manutenção principalmente do mito da democracia racial.

A educação, de forma alguma, deve ser vista como fator responsável pela segregação da 
heterogeneidade que compõe a sociedade. Ela deve ser capaz de ampliar o tema, levando os sujeitos a refletirem sobre as multifacetas das identidades, sejam elas culturais, raciais, étnicas ou de gênero que a compõe e constituem o multiculturalismo presente. É de suma importância oferecer uma análise crítica sobre a educação voltada para as questões étnico-raciais. Embora consideremos importante a presença de disciplinas que contemplem tal questão, é preciso reconhecer que ainda não são o bastante para a formação de profissionais e principalmente, futuros professores capacitados e preparados para abordar a temática de forma crítica e reflexiva no ambiente escolar tendo em vista que a carga horária é muito pequena e são poucas aquelas que oferecem a prática como momento para execução da práxis pedagógica.

Concordamos que quando se trata de questões como estas, que envolvem preconceito e discriminação e que são, sobretudo, essenciais e fundamentais para a caracterização do país, abordar a temática em apenas alguns cursos, com carga horária reduzida e optativa, coloca a temática em segundo plano e não permite a formação de profissionais preparados para lidar com as questões de cunho étnico-racial dentro do espaço escolar.

Ressaltamos ainda que o estado do Mato Grosso do Sul possui a especificidade de fazer fronteira com países como Bolívia e Paraguai o que contribui para um grande fluxo de imigrantes e possui também várias aldeias indígenas que são importantes para a constituição do povo sulmato-grossense e que ainda precisam ter os seus direitos garantidos como povo, além do povo afrodescendente que constitui boa parte da população brasileira. A Universidade teria como importante função o redobramento da atenção com projetos e ações em prol dessas discussões.

Embora alguns dos cursos ofereçam a disciplina, parece-nos ser insuficiente o espaço ocupado por estas no currículo para a formação de professores capazes de contribuir para o trato das questões étnico-raciais, conforme resultados de investigação anterior realizada a respeito do trabalho desenvolvido nas escolas durante a trajetória estudantil de três gerações distintas de estudantes (SILVA; SILVA; FLORCENA, 2019).

As universidades, por se tratarem de instituições formadoras e preparatórias destacando aqui as licenciaturas, mas não descartando a necessidade da temática em todos os cursos - sem exceção, devem ser levadas a uma discussão das propostas curriculares que norteiam a grade curricular dos cursos de licenciatura.

A universidade precisa repensar sobre a questão, de maneira a tentar superar a ausência da temática no currículo dos cursos de ensino superior. Ignorar a questão apenas contribui para consolidação do preconceito e racismo já enraizados. A formação dos profissionais para o trabalho com as relações étnico-raciais é fundamental no que diz respeito a educação de crianças, jovens e adultos e, portanto, durante o processo de formação de professores, é necessário que questões como o preconceito e a discriminação, sejam temas determinantes, e não apenas tidos como objeto de estudo de uma disciplina ou outra, e provenientes de um caso evidente na escola ou universidade. A escola apresenta deficiências no debate das questões de temática étnico racial pois, a mesma passa a abordar a temática e a cultura apenas em datas comemorativas ou devido a um caso de racismo proveniente do convívio escolar. A biblioteca da escola, importante local de fundamentação cultural a partir da leitura, deve apresentar em suas prateleiras livros que proporcionem o maior contato com essas questões e que ajudem os estudantes a compreender a importância dos negros.

A abordagem da temática representa uma formação mais completa, de um sujeito capaz de refletir sobre a constituição das relações de identidade e do multiculturalismo presente na sociedade e no seu meio social, capaz de transformar a realidade e romper com os paradigmas existentes, aumentando as possibilidades para a superação das desigualdades. É preciso ter em mente a importância do processo de formação de professores e, sobretudo, compreender a necessidade do preparo e tratamento de informações e conteúdos como este.

Mais do que repensar a educação, é preciso avançar no que diz respeito aos currículos, de modo a propor mudanças em suas estruturas para que contemplem e trabalhem conteúdos relacionados à temática étnico-racial.

\section{CONCLUSÕES}

A partir do levantamento realizado acerca da temática étnico-racial inserida nos cursos de licenciatura da universidade analisada e retomando a questão que motivou a investigação, saber: "o currículo ofertado pela 
instituição atende ao texto da política para as licenciaturas de modo que potencialize a formação docente e as práticas de ensino para a igualdade étnica ou representam uma mera formalidade?" Temos indícios iniciais para acreditar que as relações étnico-raciais não têm sido contempladas da maneira como deveriam ser abordadas, já que o tema não assume uma posição relevante perante os currículos da educação básica e ensino superior. O que se nota, é que tanto a disciplina de Educação Para As Relações Étnico-Raciais, quanto o Ensino da História e Cultura Africana e Afro-Brasileira ou indígenas, ainda são menosprezadas tanto pela abordagem sucinta, quanto pela insuficiência de carga horária teórica e prática.

Apontamos a necessidade de mais disciplinas que dialoguem com a temática aqui discutida. Ainda que existam leis e regimentos que norteiem e integrem o multiculturalismo no currículo, sabemos que não há a devida inclusão dos conteúdos nas salas de aula da educação básica e superior, o que representa um déficit gigantesco no que diz respeito a educação, uma vez que a consideramos instrumento capaz de transformar a sociedade e também as relações sociais.

Enxergar a universidade como o espaço em que se concentra uma grande diversidade cultural, e considerá-la capaz de combater toda e qualquer discriminação presente no país é uma forma de reconhecimento e visibilidade para o tema e também uma oportunidade de ofertar uma formação docente qualificada.

Diante disso, é preciso romper com esse currículo e modelo de formação atual, para que se possa repensar um currículo multicultural e reflexivo de formação de professores para a educação das relações étnico - raciais.

Faz-se necessário um novo arranjo na estrutura curricular dos cursos de graduação, uma vez que disciplinas que tratem das questões étnicos-raciais são fundamentais para o preparo do futuro docente no seu trabalho com as crianças.

No entanto, pôr em prática a educação das relações étnico-raciais diz respeito a muito mais do que a inclusão de componentes curriculares nos cursos de licenciatura e nas escolas de educação básica. Para que isso aconteça, é preciso fazer mais do que incluir a temática em apenas uma disciplina no currículo e na prática docente. Faz-se necessário uma mudança no fazer pedagógico, redimensionando os olhares para um trabalho voltado para a valorização da história e cultura desses povos. Tal ação exige que a escola e instituição estejam dispostas a romper paradigmas e vivenciar dentro do cotidiano, experiências de vida e práticas culturais voltadas para a valorização.

Assim, mais do que entender a relevância do processo de formação de professores, urge compreender, por meio de Paulo Freire (1996), que embora diferentes entre si, quem forma se forma e re-forma ao formar, e quem é formado, forma-se e forma ao ser formado. Portanto, consideramos que o professor bem capacitado é capaz de promover uma educação que valorize cada cultura, uma educação multicultural, capaz de formar indivíduos empenhados no combate contra qualquer preconceito e discriminação presentes na sociedade.

\section{REFERÊNCIAS}

ARROYO, M. Currículo, território em disputa. Petrópolis: Vozes, 2011.

BRASIL. Assessoria de Relações Públicas da Presidência da República. A Divisão de Mato Grosso - ARP. Brasília, 1977.

BRASIL. Lei de Diretrizes e Bases da Educação Nacional no 9394 de 20 de dezembro de 1996. Brasília, 1996.

BRASIL. Lei no 10.639, de 9 de janeiro de 2003. Altera a lei n. 9.394, de 20 de dezembro de 1996, que estabelece as diretrizes e bases da educação nacional, para incluir no currículo oficial da rede de ensino a obrigatoriedade de temática "História e Cultura Afro-Brasileira", e dá outras providências. Diário Oficial da União, Brasília, DF, 10 jan. 2003.

BRASIL. Lei no 11645 de 10 de março de 2008. Altera a Lei no 9.394 , de 20 de dezembro de 1996, modificada pela Lei no 10.639, de 9 de janeiro de 2003, que estabelece as diretrizes e bases da educação nacional, para incluir no currículo oficial da rede de ensino a obrigatoriedade da temática "História e Cultura Afro-Brasileira e Indígena". Brasília, 2008 Disponível em: http://www.planalto.gov.br/ccivil_03/_Ato20072010/2008/Lei/L11645.htm. Acesso em: $10 \mathrm{de} \mathrm{fev}$ de 2019. 
BRASIL. Lei no 12711, de 29 de agosto de 2012. Brasília, 2012. Disponível em: http://www.planalto.gov.br/ccivil_03/_ato20112014/2012/lei/l12711.htm. Acesso em: 10 de out. 2018.

BRASIL. Resolução no 01 de 17 de junho de 2004. Parecer homologado no Diário Oficial da União em 19 de maio de 2014. Disponível em: http://portal.mec.gov.br/dmdocuments/cnecp 0 03.pdf. Acesso em: 06 mar. 2019.

BRASIL. Constituição (1988). Constituição da República Federativa do Brasil. Brasília: Senado Federal, 1988. Disponível em: http://www.planalto.gov.br/ccivil 03/constituica o/constituicao.htm. Acesso em: 03 ago. 2019.

CARDOSO, I. A; CASTRO, R. M. A ausência/presença das relações étnico-raciais nos currículos dos cursos de pedagogia: o caso da Unesp/Marília. Práxis Educacional, Vitória da Conquista, v. 11, n. 18 p. 91-115 jan./abr. 2015.

CHAGAS, W. F. Educação das relações étnicoraciais na formação de professores (as) de história: uma prática extensionista. Cadernos Imbondeiro. João Pessoa, v. 3, n. 2, 2014.

CROCETTA, R. R. J. As relações étnico-raciais nos currículos dos cursos de licenciatura em educação física das instituições de ensino superior do sistema acafe. 2014. 99f. Dissertação (Programa de Pós-Graduação em Educação) Universidade do Sul de Santa Catarina, 2014.

DIAS, L. R. Formação de professores, educação infantil e diversidade étnico-racial: saberes e fazeres nesse processo. Revista Brasileira de Educação, v. 17 n. 51 set./dez. 2012. https://doi.org/10.1590/S1413-

$\underline{24782012000300010}$

DIAS, L. R. Diretrizes Curriculares Nacionais para a Educação das Relações Étnico Raciais e para o Ensino de História e Cultura Afro-Brasileira e Africana. Brasília: MEC, 2004.

FLEURI, R. M. Intercultura e Educação. Revista Brasileira de Educação. 2003, n. 23, p. 16-35. https://doi.org/10.1590/S1413$\underline{24782003000200003}$
FUNDAÇÃO NACIONAL DO ÍNDIO (FUNAI). Povos indígenas. Disponível em http://www.funai.gov.br. Acesso em: 6 abr. 2019.

GIL, A. C. Como elaborar projetos de pesquisa. 4. ed. São Paulo: Atlas, 2008.

GODOY, E. A. A ausência das questões raciais na formação inicial de professores e a Lei 10.639/03. Rev. educ. PUC-Camp., Campinas, v.22, n.1, p.77-92, jan./abr., 2017. https://doi.org/10.24220/P1519-3993$\underline{2017220100006}$

GONÇALVES, F. L. C. Papel da Escola na Desconstrução do Racismo, Preconceito e Discriminação: a Fomentação Profissional dos Educadores da Escola Estadual de Ensino Fundamental Presidente Castelo Branco. 2018. Disponível em: <http://www.sinprodf.org.br/wpcontent/uploads/2012/01/papel-da-escola-nadesconstru\%C3\%A7\%C3\%A3o-do-racismo1.pdf $>$. Acesso em: 07 set. 2018.

GOMES, N. L. Diversidade étnico-racial: por um projeto educativo emancipatório. In: FONSECA, M.V.; SILVA, C.M.N.; FERNANDES, A. B. Relações étnico-raciais e educação no Brasil. Belo Horizonte: Mazza Edições, 2011. p 39-60.

GOMES, N.L.; SILVA, P.B.G. O desafio da diversidade. In: GOMES, N.L.; SILVA, P.B.G. Experiências étnico-culturais para a formação de professores. Belo Horizonte: Autêntica, 2002, p. 13-34.

ORGANIZAÇÃO DAS NAÇÕES UNIDAS - ONU. Declaração Universal dos Direitos Humanos. 1948. Disponível em: <http://www.onu.org.br/img/2014/09/DUDH.pdf >. Acesso em: 07 set. 2018.

ORGANIZAÇÃO DAS NAÇÕES UNIDAS - ONU. Convenção Internacional sobre a eliminação de todas as formas de discriminação racial. 21 de dezembro de 1965. Disponível em: $<$ http://www2.camara.leg.br/atividadelegislativa/comissoes/comissoespermanentes/cdhm/comite-brasileiro-dedireitos-humanos-e-politicaexterna/ConvIntElimTodForDiscRac.html>. Acesso em: 08 set. 2018. 
PASSOS, J. C. As relações étnico-raciais nas licenciaturas: o que dizem os currículos anunciados. Tubarão. Poiésis, (Unisul), v. 8, p. 179-196, 2014. https://doi.org/10.19177/prppge.v8e132014172$\underline{188}$

SALES JR., R. Democracia racial: o não-dito racista. Tempo social. Revista de sociologia da USP, São Paulo, SP, v. 18 , n. 2, p. 229-258, nov. 2006. https://doi.org/10.1590/S0103$\underline{20702006000200012}$

SALES JR., R. Secretaria de Educação Fundamental. Parâmetros Curriculares Nacionais: pluralidade cultural, orientação sexual. Brasília: MEC/SEF, 1997.

SILVA, F. L; SILVA, T. P; FLORCENA, A. A abordagem das relações étnico-raciais no currículo escolar: Uma retrospectiva ao longo de três gerações. Revista Formação Docente, 2019 (no prelo).

SILVA. T. T. Documento de identidades: uma introdução às teorias do currículo. 3. ed. Belo Horizonte: Autêntica, 2011.

XAVIER, C. F. Luz, camêra, ação... Problematizando sexualidades, gênero e infâncias no cinema: desejo de "desver" o mundo. Campo Grande, MS: Editoria UFMS, 2014. 9-27p.

TARDIF, M. Saberes docentes e formação profissional. 5. ed. Petrópolis, RJ: Vozes, 2005.

ZEICHNER, K. Formação de Professores: Contato direto com a realidade da escola. Presença Pedagógica, v.6, n. 34. Jul/ago 2000. p. 5 -15. 